1 Publisher: Taylor \& Francis

2 Journal: Archives of Environmental \& Occupational Health

$3 \quad$ DOI: https://doi.org/10.1080/19338244.2018.1461601

4

5

6 Title:

7 Fire Service Instructors' Working Practices: A UK Survey

8

9 Running head:

10 Fire Service Instructors' Survey

11

12

13 Title:

14 Fire Service Instructors' Working Practices: A UK Survey

15

16 Running head:

17 Fire Service Instructors Suryey

18

19 Authors:

20

Emily R Watkins BSC

E.R.Watkins@brighton.ac.uk

Corresponding author

21 Mark Hayes Phí

22

Peter Wác PhD

23 Alan J Richardson PhD

24

25 Affiliation and address of all authors: 
BN20 7SR, UK.

Authors' contribution to the study:

Emily R Watkins

Study design, survey preparation, survey distribution, data analysis, manuscript write up

\section{Mark Hayes}

Study design and manuscript write up

Peter Watt

Study design and manuscript write up

\section{Alan J Richardson}

Study design, survey preparation, survey distribution, and manuscript write up

\section{ABSTRACT}

Analysis of Fire Service Instructors (FSI) working practices and health is needed to minimise health risks related to heat illness, cardiovascular events and immunological stress. Online surveys were distributed to UK FSI and Firefighters (FF). One hundred and thirty FSI (age: $43 \pm 7$ rrs ) and 232 FF (age: 41 \pm 8 yrs) responded. FSI experienced 2-10 live fires per week, with $45 \%$ of FSI reporting management does not set a limit on the number of exposures. Few FSi followed hydration guidelines, or cooling methods. New symptoms of ill health were reported by $41 \%$ of FSI and $21 \%$ of FF. FSI with $\geq 11$ Breathing Apparatus exposures per month were 4.5 times (95\% CI 1.33-15.09) more likely to experience new symptoms. A large proportion of FSI are experiencing new symptoms of illness after starting their career, and guidelines on exposure and hydration are not universally in place to reduce the risk of future health problems. 


\section{KEY WORDS}

58 Fire service; Occupational health; Heat exposures

59

60 ABBREVIATIONS

61 BA Breathing apparatus

62 CFBT Compartment fire behaviour training

63 CRP C-reactive protein

64 EHI Exertional heat illness

65 FF Firefighters

66 FSI Fire Service Instructors

67 IL-6 Interleukin-6

68 URTI Upper respiratory tract infection 

91 mortality. ${ }^{12}$

\section{INTRODUCTION}

Fire Service Instructors (FSI) are responsible for training newly recruited and operational firefighters. Instructors who teach on Breathing Apparatus (BA) and Compartment Fire Behaviour Training (CFBT) courses experience live fire scenarios (wears) on a regular basis A wear is defined as a period in which an individual is breathing via a BA. Acute wear exposure can cause high levels of physiological and perceptual strain, due to the extreme environment, heavy protective clothing worn, and physical activity compleed. ${ }^{1,2}$ FSI and firefighters (FF) may also experience dehydration, ${ }^{1,3}$ smoke and carcinsgen inhalation, which can cause breathing difficulties, ${ }^{4}$ and regular high impact tasks and hanailng of heavy objects, which may lead to muscular pain.,

Frequent fire exposure may also put FSI at risk of carciac-yelated events, which are the highest cause of death amongst FF, accolnting for $56 \%$ of US FF deaths in 2014 . $^{7}$ The odds of a FF suffering a cardiovascular event are 12.1 to 136 times higher during fire suppression than when conducting nonemergercy duties. ${ }^{8}$ Numerous inflammatory markers, such as interleukin-6 (IL-6), platelet number, and C-reactive protein (CRP), have been documented to increase following fire exposure. ${ }^{9}$ Repeated wears may therefore have a chronic effect on these markers. ${ }^{1}$ poleitially increasing an instructor's risk of a cardiac event. During an acute wear FSI are aIss at risk of suffering from an exertional heat illness (EHI). ${ }^{10}$ The extreme temperature, which can reach $174.0 \pm 83.9^{\circ} \mathrm{C}$, combined with heavy encapsulating clothing, and moderate physical exertion causes an uncompensable heat stress environment, reducing

90 an instructors ability to dissipate heat. ${ }^{11}$ In severe cases EHI can lead to organ failure and could be reduced. There is strong evidence advocating the use of methods, such as: post 
94 exposure arm cooling, ${ }^{11,13}$ adequate hydration status, ${ }^{3,11}$ and ice slurry pre cooling, ${ }^{14}$ to reduce the risk. The latest "Health Management of Training Centre Instructor's" report suggests that individuals drink 1.5 times the amount of fluid lost during heat exposure, with case study examples of $\sim 750-800 \mathrm{~mL}$ prior to exposure, $\sim 400-1000 \mathrm{~mL}$ taken on during the activity and 1000mL post exposure given. ${ }^{15}$ The report also suggests a minimum of $2 \mathrm{hr}$ between exposures, with cooling methods such as ice slurry, forearm cooling, dress down prncedures, and wearing ice vests all recommended. ${ }^{15}$ There is no clear guidance on wear limits. only that it is important to instigate a method to safeguard instructors' health. ${ }^{15}$ However, it is unknown if instructors in the UK have been directly provided with and are following this advice.

In addition, as a result of repeated wear exposures recent research suggests FSI may be at risk of overtraining. ${ }^{1}$ Overtraining syndrome can be recpgnised by a prolonged maladaptation to several biological, neurochemical and hermonal regulation mechanisms, with confounding factors such as illness, inadequate nutrition, psychosocial stressors and sleep disorders, potentially being present. ${ }^{16} \mathrm{It} / \mathrm{Can}$ develop due to a repeated exposure to stress leading to an altered responsiveness to subsequent stressful experiences, with reference usually given to high training loads. Furthermore, overtraining and extremely heavy exercise have been previously linked to increased susceptibility and rates of upper respiratory tract infections (URTI) and ilinesses, due to immunosuppression. ${ }^{17}$

Gvertraining symptoms have previously been documented in Army recruits during training courses, ${ }^{18}$ with prevalence amongst special military unit training suggested as being $24 \%$ of participants. ${ }^{19}$ The prevalence of overtraining varies greatly amongst athletes, from $10-64 \%$, with numbers altering based on the level of physical demand required for the sport and the duration of participation. ${ }^{20-24}$ However, it is important to note that there is no single universally used diagnostic tool for overtraining, which may influence the prevalence rates 
119 reported. ${ }^{25}$ Amongst FSI, symptoms of overtraining have only been anecdotally reported. For FSI overtraining may not only be detrimental to their health but also to their occupational

121 functionality, with loss of coordination, difficulty concentrating, and a reduced maximum

139 informed that individual responses would be kept confidential, and therefore would not be 140 provided to their superior colleagues. The study was approved by the University of Brighton work capacity. It is therefore important to identify the type and frequency of symptoms and illnesses experienced by FSI to form the basis for further investigation into the proposed overtraining response that repeated wear exposures may cause.

The purpose of the present study was therefore to document the working practres of FSI in comparison to FF, from across the UK, with specific reference to details of: vrear types completed, preparation and recovery methods used, and illnesses and symptoms experienced.

A secondary objective was to identify associations between new svmptoms reported by FSI and the number of wears they completed, if they follow hyduration guidelines, and their perception of recovery.

\section{METHOD}

Within the UK there are 300 FSI and approximately 34,400 FF, across Fire and Rescue Services and private training prsviders. To establish the common demographics and working practices of instructers within the UK, in comparison to FF, both groups were invited to take part in an online survey. The survey was advertised across the UK via direct emails and social media. Those who responded to the survey and left their email address were contacted to ask them to further distribute the survey to their colleagues. The survey was also distrituted upon visits to UK Training Centres and Fire Stations. All participants were ethics committee and conformed to the current Declaration of Helsinki guidelines (2013). 
Prior to the survey a focus group was held with FSI from the "Health Management Research Project for Live Fire Instructors" to shape the direction of the questions and ensure the content was appropriate for the desired population. The focus group also identified the types of wears instructors complete, these were listed as: BA, CFBT, and BA cold/no smoke exposures. The focus of BA cold/no smoke and BA wears are for the students to be familian with and learn how to use the equipment, whilst CFBT focuses on understanding how fire behaves and how to extinguish it. BA cold/no smoke wears involve learning how to use bA equipment in a temperate environment, however it should be noted PPE is worn and therefore elevated core temperatures may still occur. BA wears involve expostires to high environmental temperatures with instructors responsible for following teams of students to coach them when required. CFBT uses controlled live fires, where instructors coach students or remain outside the fire unit to control the environment with ventilation. Full details of the aim of exposures can be found in the SFJ Awards Qualification Handbook. ${ }^{26}$ Preparation and recovery methods used at training centres were also suggested.

\subsection{The Survey}

A survey was generated using an online survey tool (surveymonkey.com, California, Palo Alto, USA). The survey consisted of 6 sections, covering demographics, wear types, preparation recevery, illnesses, and an option to give any additional comments. After corrections based on pilot feedback the survey consisted of 36 questions, please see the supplementary material for the survey questions. Details of respondents' age, gender, and time as an instructor were gathered, alongside how often they completed each type of wear and which wear they found the most physically challenging. FSI do not regularly complete other wear types, however an open response box was available for them to give details of other working practices and exposures if relevant. Questions orientated around preparation and recovery included whether they had a routine, what methods they used, and how long 
they prepared/recovered for. Instructors were also asked how often they were ill, what type of symptoms they experienced, and if they felt comfortable requesting sick days. Language used throughout the survey was non-biased, with neither positive nor negative phrasing of the introduction and questions.

A shorter version of the survey, containing 10 questions, was designed for firefighters. The questions were taken from the demographic, wear frequency, and illness sections of the instructor survey. The surveys were live for 12 months.

\subsection{Statistical Analysis}

Demographic quantitative data is displayed as Mean \pm Standard Deviation (SD). A MannWhitney U test was conducted to analyse differences in interval data between FF and FSI when normal distribution assumptions were violated, as determined by a Shapiro-Wilk test. Prevalence of categorical data responses are reperted in frequencies and percentages, with Pearson's chi square analysis performed to assess if the distribution of categorical variables differ from one another. A Fislier s exact test was used when $>20 \%$ of expected frequencies within each category were less than 5 . Subsequent odds ratios and 95\% confidence intervals (CI) were calculated to analyse associations. Significance level was set at $\mathrm{p}<0.05$. Qualitative responses to spen questions were categorised into key themes.

\section{RESILTS}

The survey was completed by 130 FSI and 232 FF; response numbers for individual questions vary, as questions that did not apply could be skipped. Table 1 details the demographic of responders. All participants completed the survey within two days of initial engagement with the questions. Fisher's exact tests revealed that FSI responses did not differ 
by time of year of survey completion for reported wear numbers (BA: $p=0.81$, CFBT: $p=0.159$, BA cold/no smoke: $p=0.464)$ or new symptoms of ill health $(p=0.296)$.

\subsection{Wear Types}

The frequency of wear types completed by FSI in the previous month is presented in Figure

1. Overall the median number of wears completed by FSI ( \pm interquartile range, was 13 \pm 8 , with the minimum number experienced being 0 and the maximum being 40 . W'hen broken down into wear types, FSI completed $5 \pm 6$ BA wears, $3 \pm 5$ coidi/no smoke wears, and $3 \pm 4$ CFBT wears. The mode duration of a BA wear 4 as $25-30$ minins reported by 24 (23\%) FSI, 36-40 mins for CFBT reported by 21 (20\%), FSI, and $26-30$ mins for BA cold/no smoke reported by 22 (23\%) FSI.

The median number of live fire wears experienced by FF was $1 \pm 3$, with 214 (92\%) FF having completed $\leq 5$ wears in the previous month. Oniy 17 (13\%) FSI completed $\leq 5$ wears in a month.

When asked to order the wear types by bow physically straining they found them, 60 (59\%) reported that CFBT generated the greatest strain, and 78 (76\%) FSI selected BA cold/no smoke as the least strainirig, see Table 2.

Of the respondents 39 (35\%) FSI thought that they completed too many wears in a week, and 50 (45\%) reported that they were unaware of any wear limit set by management. Of those who diu have a limit (62, 55\%), it ranged from 2-10 per week.

\section{2. Preparation for Wear}

Seventy-nine (73\%) FSI were not allocated a period to prepare for a wear. Preparation methods used by FSI are displayed in Figure 2. The alternative methods reported by 20 (20\%) FSI were grouped into themes and included: drinking water, checking tympanic temperatures, 
and using rehydration sachets. Some FSI (15, 15\%) used multiple methods of preparation, with the most common combinations being hydration checks with wearing a phase change vest (FSI: 6, 6\%) and hydration checks with ice slurry consumption (FSI: 5, 5\%). Having no hydration guidelines was reported by 44 (41\%) FSI. Those with guidelines reported using visual charts to check urine colour and specific advice from within their service on water consumption.

\subsection{Recovery from Wear}

Seventy-six (70\%) FSI also stated that they do not have a set allocated recovery time; FSI from organisations with a specified recovery time had a minimum of 2 hours between wears allocated. However, 18 (55\%) of those with a set recovery time reported having an actual average recovery period of less than 2 hours. A verage recovery periods ranged from $5 \mathrm{~min}$ to $2 \mathrm{hrs}$, with $31(32 \%)$ FSI having $\leq 15 \mathrm{~min}$ and $44(45 \%)$ having $>30 \mathrm{~min}$. Those that had >30min reported having additional tasks to de in that time, including debriefing students, paperwork and eating lunch. Recovery methods used are displayed in Figure 2. Themes of alternative methods included using rehydration sachets and dress down procedures. Some FSI (24, 24\%) used multiple methods of recovery, with the most common combinations being drinking water sitn rehydration sachets (FSI: 8, 8\%), and drinking water with forearm cooling (FSI: $9,9 \%)$.

Only 3 (3\%) FSI reported that they felt fully recovered after their recovery period, with the majority, 71 (65\%), stating they were only just recovered, feeling worn out and warm. A

32 further 9 (8\%) FSI were exhausted and hot after a wear and did not feel recovered.

\subsection{Illness}


Over the previous year FF reported taking a greater number of sick days compared to FSI (3 \pm 7 vs. $1 \pm 3$, respectively), $U=18446, p<0.001$. However, 49 (45\%) FSI also reported that they did not feel comfortable reporting illness at work and taking sick leave. Participants were asked to recall periods of cold or flu over the last year, with 27 (25\%) FSI having not suffered from a cold or flu, 60 (55\%) had one or two occurrences, 20 (18\%) had suffered 3-6 times, 1 (1\%) had symptoms once a month, and 2 (2\%) suffering 2-4 times a month $\ln$ comparison, 51 (22\%) FF reported no cold or flu occurrences, 134 (59\%) had symptonis once or twice in the year, 40 (18\%) suffered 3-6 times, and 4 (2\%) had a cold or flu once a month.

When FSI were asked if they frequently suffer from any other ilinesses or symptoms that they did not experience prior to becoming an instructor, 45 (41\%) said Yes. Some (48 (21\%)) FF also reported suffering from a new illness or symptoms that they did not experience before becoming a FF.

There was an association between the number of $B A$ wears completed $(\leq 5,6-10$, or $\geq 11$ a month) and presence of new symptoms, $\chi^{2}(2)=6.37, p=0.041$. The odds of suffering from a new illness or symptom was 1.6 (95\% cI 0.66-3.66) times higher for FSI who conduct 6-10 BA wears a month, and 4.5 ( $35 \%$ CI 1.33-15.09) times more likely when completing $\geq 11$ BA wears, compared to those who completed $\leq 5$. There was no association between those suffering from new symptoms and those who had hydration guidelines, $\chi^{2}(1)=0.60, p=$ 0.691 How recovered FSI felt after their wear recovery (fully recovered, fine, worn out and warm, and exhausted) was associated with the presence of new symptoms, ( $p=0.004$, Fishar's Exact Test). Those who felt exhausted after a wear were 16.8 (95\% CI 2.69104.82) times more likely to suffer a new symptom than those who felt fine afterwards. New symptoms reported by FSI were: fatigue (16), headaches (12), broken sleep (8), musculoskeletal pain (8), heavy sweating (6), problems thermoregulating (5), heart 
palpitations (4), blood shot eyes (3), mood swings (3), and coughing and breathing problems

259

260

261

262

263

264

265

266

267

268

269

270

271

272

274

275

276 277 are provided with, or follow, the advice on hydration and recovery methods suggested in the

(4). The common themes from FF were: back pain (11), post-traumatic stress disorder (PTSD) or depression (7), coughing or breathing problems (10), and headaches (5).

FSI and FF were also asked how they felt both physically and mentally at the end of a working week, results shown in Table 3.

\subsection{Additional Comments}

From the 39 (30\%) FSI who left additional comments, the key themes were: frecuently feeling fatigued (4), being worried about their health (4), concern over the number of wears (14), lack of fresh protective clothing (5), worry about breathing in contaminants (4) and support for hydration and cooling methods to reduce the acute effects of a wear (4).

\section{DISCUSSION}

The study aimed to document the working prictices of FSI across the UK, to enable a better understanding of the frequency of heat exposures, the types of preparation and recovery methods used, and the prevalence and type of illnesses experienced. FF were used as a comparative group. The study also aimed to establish whether there was an effect of wear number, hydration adyice, or perception of recovery on the presence of overtraining symptoms ar ingess The number and duration of wears completed varied, however a larger proportion of FSI completed 6-10 BA wears a week than CFBT, with FSI completing a greater number of wears than FF. The findings from this survey also suggest that not all FSI research literature. Furthermore, the prevalence of new symptoms and illnesses since starting the occupation is high (41\%), with prevalence potentially linked to high wearing numbers and 
poor recovery. Some FF also experience new symptoms (21\%), although of a different nature to FSI.

\subsection{Wear Types}

The variety of wear frequency and duration reported was as expected based on previous findings. ${ }^{1,10}$ It is clear that whilst the majority of FSI have a limit to the number of wears the can complete, as recommended by the Chief Fire Officers Association guidance, there is not a universal practice. There is also large variation in the number of permitteri weats set by each service, however there is currently no evidence based literature to support either the conservative or liberal prescription. Additionally, some FSI (4) report a very high limit ( $\geq 8$ per week) of heat exposure frequency. This study also showed data that suggests FSI who complete $\geq 11$ BA wears a week are 4.5 times more likely to experience new symptoms or illnesses.

Repeated heat exposures may cause chronic inflammation in FSI, with elevated resting Creactive protein $(\mathrm{CRP})\left(7378+3770 \mathrm{ng} \cdot \mathrm{mL}^{-1}\right)$ and IL-6 levels $\left(11.4 \pm 1.0 \mathrm{pg} \cdot \mathrm{mL}^{-1}\right)$ previously documented. ${ }^{1}$ Inflammatien plays a role in both the initiation and progression of atherosclerosis. ${ }^{27}$ Elesated leveis of inflammation, exacerbated by reduced recovery time between wears, 9 sıggests that FSI may be at an increased risk of a cardiovascular event as the

297 frequency of heat exposures rises.

\subsection{Preparation and Recovery}

299 This study also highlights the need for additional hydration education, as 44 (41\%) FSI were

3c0 unaware of any hydration guidelines. This is despite guidelines indicating that 1.5 times the

301 amount of fluid lost during exposure should be consumed. ${ }^{15}$ During a wear FSI have been

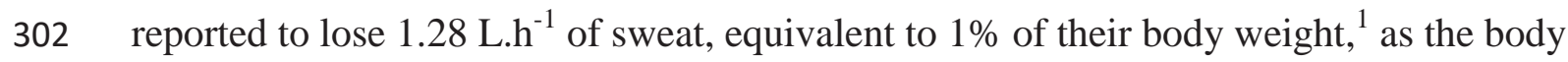


attempts to dissipate heat via sweating. However, some FSI carry out wears multiple times a day, and consequently may become progressively hypohydrated. ${ }^{28}$ A reduction of body weight post exercise of $\geq 2 \%$ can cause decrements in both psychological and physiological performance, for example increasing decision making time and reducing fine motor skill accuracy. ${ }^{28,29}$ However, no association was present between those who used hydration guidelines and FSI who reported new illnesses and symptoms.

Pre cooling may be a practical intervention available to FSI to reduce the phystological strain experienced during a wear, and is recommended by national FSI guidelines. ${ }^{15}$ The reduction of core temperature prior to exercise in the heat via cooling metlods is a weil-established technique amongst athletes, as it can increase the body's heat storage capacity, enabling individuals to maintain their work intensity for longer, or reduce their end core temperature. ${ }^{30}$

314 There are various pre cooling methods available, including cold water immersion, ${ }^{31}$ ice

315 jackets, ${ }^{32}$ and ice slurry consumption, ${ }^{33}$ which have been reported to reduce core temperature prior to exercise by $0.3-0.7^{\circ} \mathrm{C} .{ }^{30}$ Howrever, it is unclear which method of cooling is most beneficial for FSI, with specifir advice on duration and dosage also currently not provided. ${ }^{15}$ Consequently, further resparch is needed into the use of practical pre cooling methods for FSI, with the need for this research to be fed into FSI guidelines.

Additional information on the use of post cooling techniques should also be provided to FSI, as despite scientific literature and FSI guidelines supporting the use of various methods, little

322 is being nractically applied in the UK. Cheung et al., ${ }^{11}$ offers a comprehensive review of the 323 use of recovery forearm immersion cooling for firefighters. However, a more recent review

324 by Brearley \& Walker reported that hand and forearm cooling results in an unacceptable

325 cooling rate of $<0.07^{\circ} \mathrm{C} \cdot \mathrm{min}^{-1}{ }^{34}$ Ice slurries may offer a practical alternative, with cooling rates of $0.09^{\circ} \mathrm{C} \cdot \mathrm{min}^{-1}$ having been reported post live fire exposure. ${ }^{35}$ 
The responses to questions about recovery time in this survey highlight that few FSI have a period to rest and cool down, without other demands made of them. To discover what FSI view as a recovery period the questions in this survey were kept broad, asking only if they were allocated specific recovery time, the average recovery time experienced, and an option to provide details. The questions did not specify what should occur in the recovery time. Responses indicate that the recommended $2 \mathrm{hr}$ minimum between heat exposures is thought of by some FSI as their recovery period, ${ }^{15}$ and can involve other tasks and often covers the lunch break period. However, FSI are often not receiving a full 2 hr period between wears. Guidance for providing adequate time to rest immediately post a wecr, when rehydration and cooling can occur, should be considered.

\subsection{Illness}

Prevalence of cold and flu symptoms amongst FF and FSI were similar, with $22 \%$ vs $25 \%$ not experiencing symptoms, $59 \%$ vs $55 \%$ having one or two occurrences, and $19 \%$ vs $21 \%$ suffering more than 3 times a year This is similar to the prevalence of cold and flu amongst a normal European population grsup have previously been reported with 25\% hardly ever catching a cold, 50\% experiencing symptoms once or twice a year and 21\% suffering 3-4 times a year. ${ }^{36}$ This suggests that FF and FSI do not sufferer from a greater number of URTI.

A greater proportion of FSI reported experiencing new symptoms (41\%) than FF (21\%). Two symptoms crossed over both groups: headaches, and coughing and breathing problems. FF have previously been reported to have a high prevalence of dyspnea, coughs, and sinusitis, alongside lower forced vital capacities $(5.09 \pm 0.68 \mathrm{~L})$ and forced expiratory volume in one second (4.06 $\pm 0.56 \mathrm{~L})$ compared to predicted values $(5.26 \pm 0.61$ and $4.38 \pm 0.54$, respectively) $\mathrm{p}<0.05 .{ }^{37} \mathrm{FF}$ have also been reported to have an increased risk of developing adult-onset asthma compared to police officers $(\mathrm{OR}=1.23) .{ }^{38}$ Exposure to air pollutants, from 
combustion products, is the probable cause of these symptoms, as they have been documented to exacerbate respiratory symptoms and increase bronchial reactivity. ${ }^{4,39}$

Minimising exposure to "dirty" PPE and the use of effective decontamination processes,

the training ground and during overhaul situations, may reduce individual's exposyre

\section{to toxic air contaminants. ${ }^{40}$ Future investigation into the practices used within the UK}

fire service, with reference to the effectiveness of different processes, could be warranted.

359

360

361

362

FF also reported experiencing back pain. Previous studies have cocumented that up to $44 \%$ of FF may suffer from back pain, with this percentage rising with trme in service. ${ }^{41}$ The additional weight carried by FF due to PPE and BA, combined vith reduced ankle flexibility caused by restrictive boots, may result is additionai compressive forces on the spine. ${ }^{5}$ Frequent heavy lifting and wearing PPE have also been reported to increase the odds (OR = 1.3) of suffering from lower back pain in the military. ${ }^{6}$ FF wear PPE to response to all emergency calls in the UK, and therefore may stand in full PPE for numerous hours, for instance when attending a road traffic collision. Consequently, these prolonged periods of PPE wearing combined witis manual tasks may explain why this symptom was prevalent amongst FF byt not FSI.

The final symptoms reported only by FF were PTSD and depression. Operational FF are 1irkely to sce traumatic events, being the first responders to a larger variety of situations. Prevalence of PTSD amongst first responders ranges from $10-32 \% .{ }^{42,43}$ Assisting survivors and exposure to fatally injured persons increases the likelihood of PTSD (OR $=2.98$ and OR $=3.40$, respectively). ${ }^{42}$ Walker et al., suggest that FF may be predisposed to PTSD, due to chronic low grade inflammation they may suffer as a consequence of altered sleep patterns, high physical workloads, injuries, and heat and smoke exposure. ${ }^{44}$ Whilst this study suggests 
that FF in the UK are not frequently exposed to fire situations, shift patterns and manual tasks could still be involved in predisposing FF to PTSD.

Amongst the new symptoms reported by FSI are those that have also been associated with overtraining. Insomnia (with and without night sweats), fatigue, mood swings, and muscle pain as reported by the FSIs in this survey are all signs of an overtraining syndrome. ${ }^{17}$

Frequent high stress experiences may lead to chronic inflammation, evident by increased It6, and have been linked to immune function dysregulation. ${ }^{45}$ Suppression of ceil inediated immune function has been hypothesised to be a leading factor in the development of overtraining syndrome. ${ }^{17}$ It can therefore be postulated that repeated exposure, of up to 10 times a week as documented in this study, could result in FSI developing a syndrome similar to that of the overtraining syndrome.

The presence of some of the new symptoms reported by FSI could also impact on their safety whilst conducting wears. Sleep deprivation is a risk factor for $\mathrm{EHI}{ }^{46}$ with partial sleep disruption increasing heat strain auring exercise in a hot environment when performed in the afternoon. ${ }^{47}$ Sleep deprivation can also increase the risk of inflammatory disease, with markers of inflammation, such as 1L-6, exhibiting a greater increase during exercise when individuals are sleep ceprived. ${ }^{48}$ With IL-6 already elevated in FSI both at rest and post wear, ${ }^{1}$ sleep deprivation may be further exacerbating the rise.

FSI aiso reported experiencing heart palpitations, which although usually benign, can be caused by arrhythmias, which include supraventricular tachycardia, ventricular extrasystoles, or atrial fibrillation. ${ }^{49,50}$ Suffering from an arrhythmia can increase the risk of sudden cardiac death (relative risk 3.2, 95\% CI 2.0-5.3). ${ }^{49}$ Atrial fibrillation is also a predictor of cardiovascular events (rate ratio 1.8, 95\% CI 1.3-2.5), with 66\% of men with atrial fibrillation experiencing an event over a 20 year period, compared to $45 \%$ of asymptomatic men. ${ }^{51}$ The 
possibly life threatening consequences of sleep deprivation and heart palpitations reported by FSI suggest that further investigation into the health of FSI is warranted, with determining methods and guidelines to reduce the incidence of these new symptoms of paramount importance.

\subsection{Limitations}

Whilst the study reports working practices of FSI compared to FF, it can only ciffer a snapshot of the UK, as not all UK Fire and Rescue Services responded to the survey. However, 33 training centres and 46 of 52 UK Services were represented in the survey. The total number of BA wears completed by FSI may be underestimated, as specific information regarding the completion of wears outside of instructing duties was not gathered. In addition, reports of illnesses were subjective, as verification by a medical professional was not obtained. Due to the subjective nature of these findings cause and effect cannot be confirmed between variables. Furthermore, participants were asked to give retrospective accounts of working prictices and illnesses, which may have resulted in recall bias. The distribution of the suryoy via word of mouth may have caused some response bias toward those suffering ir health, as they may have been more inclined to make their voice heard. However to try and initigate against this, wording of the title and intro referred only to working practicks, not health, and included non-biased language.

\section{CONCIUSION}

This survey is the first to document FSI working practices from different training centres in the UK. FF experienced few live fire situations in comparison to FSI. FSI who complete a greater number of BA wears may be at an increased risk of suffering from a new symptom or illness. Some services employ a wearing limit, which would appear to be justified good practice based on the findings of this study. Further research into how many wears can be 
conducted before negative health consequences develop is needed. Research into the benefit

425

426

427

of pre cooling methods for FSI is also required, with the need for this information, and that of effective post cooling methods, to be better fed into FSI guidelines. Some FF (21\%) are reporting new health issues, although of a different nature to FSI, with key concerns being back pain and PTSD. Overall, 41\% of FSI are experiencing new health problems after becoming instructors, with some of the symptoms reported increasing the risk of EHI and cardiovascular events. Consequently, this survey highlights the need for quantitative laboratory and field investigations into the health of FSI.

\section{ACKNOWLEDGEMENTS}

\section{REFERENCES}

1. Watt PW, Willmott AGB, Maxivell NS, Smeeton NJ, Watt E, Richardson AJ. Physiological and psychological responses in Fire Instructors to heat exposures. $J$ Therm Biol. 2015:58.105-114.

2. Petruzzello SI, Gapin JI, Snook E, Smith DL. Perceptual and physiological heat strain: exarnination in firefighters in laboratory- and field-based studies. Ergonomics. $2009 ; 52(6): 747-54$

3. McLellan TM, Selkirk GA. The management of heat stress for the firefighter: a review of work conducted on behalf of the Toronto Fire Service. Ind Health. 2006;44(3):41426.

4. Miedinger D, Chhajed PN, Stolz D, et al. Respiratory symptoms, atopy and bronchial hyperreactivity in professional firefighters. Eur Respir J. 2007;30(3):538-44. 
447 5. Vu V, Walker A, Ball N, Spratford W. Ankle restrictive firefighting boots alter the 448 lumbar biomechanics during landing tasks. Appl Ergon. 2017;65:123-129.

449 6. Roy TC, Lopez HP. A Comparison of deployed occupational tasks performed by different types of military battalions and resulting low back pain. Mil Med. 2013;178(8):e937-e943.

7. Fahy RF, Leblanc PR, Molis JL. Firefighter Fatalities in the United States-2014. Nat I Fire Prot Assoc J. 2015;(June).

8. Kales SN, Soteriades ES, Christophi CA, Christiani DC. Emergency Duties and Deaths from Heart Disease among Firefighters in the United States. $N$ Engl J Med.

9. Walker A, Keene T, Argus C, Driller M, Gay JH, Rattray B. Immune and

10. Eglin CM, Coles S, Tipten MJ. Physiological responses of fire-fighter instructors during training exercises. Ergonomics. 2004;47(5):483-94.

11. Cheung SS, Fotersen SR, McLellan TM. Physiological strain and countermeasures with firefighting. Scand J Med Sci Sports. 2010;20 Suppl 3:103-16.

12. Casa D1, Armstrong LE, Kenny GP, O’Connor FG, Huggins R a. Exertional heat stroke: New concepts regarding cause and care. Curr Sports Med Rep. 2012;11(3):115123.

467 13. Giesbrecht G. Cooling hyperthermic firefighters by immersing forearms and hands in 10 C and 20 C water. Aviat Space Environ Med. 2007;(January):561-567. Ingestion before Exertion in Wildland Firefighting Gear. Prehospital Emerg Care. 
15. Chief Fire Officers' Association. Health Management of Training Centre BAI's. 2015;(March):1-116.

16. Meeusen R, Duclos M, Foster C, et al. Prevention, diagnosis, and treatment of the overtraining syndrome: Joint consensus statement of the european college of sport science and the American College of Sports Medicine. Med Sci Sports Exerc. 2013;45(1):186-205.

17. Smith LL. Overtraining, Excessive Exercise, and Altered Immunitv Is This a T Helper-1 Versus T Helper-2 Lymphocyte Response ? Sport Med.2093;33(5):347-364.

18. Booth CK, Probert B, Forbes-Ewan C, Coad RA. Australian army recruits in training display symptoms of overtraining. Mil Med.2006;171(11):1059-64.

19. Chicharro JL, López-Mojares LM, Lucía A, et al. Overtraining parameters in special military units. Aviat Space Environ Med. 1998;69(6):562-8.

20. Raglin J, Sawamura S, Alexiou S, Hassmén P, Kenttä G. Training Practices and Staleness in 13-18-Year-Old Swimmers: A Cross-Cultural Study. Pediatr Exerc Sci. 2000;12(1):61-70

21. Kentta G, Hassmen P, Raglin JS. Training practices and overtraining syndrome in Srwedis age-group athletes. Int J Sports Med. 2001;22(6):460-465.

22. Gustafsson H, Kenttä G, Hassmén P, Lundqvist C. Prevalence of burnout in competitive adolescent athletes. Sport Psychol. 2007;21(1):21-37.

23. Matos NF, Winsley RJ, Williams CA. Prevalence of nonfunctional overreaching/overtraining in young english athletes. Med Sci Sport Exerc. 2011;43(7):1287-1294. 
508

509

510

511

512

513

24. Birrer D, Lienhard D, Williams CA, Röthlin P, Morgan G. Prevalence of nonfunctional overreaching and the overtraining syndrome in Swiss elite athletes. Schweizerische Zeitschrift fur Sport und Sport. 2013;61(4):23-29.

25. Halson SL, Jeukendrup AE. Does overtraining exist? An analysis of overreaching and overtraining research. Sport Med. 2004;34(14):967-981.

26. SFJ Awards. Using Breathing Apparatus in Fire and Rescue Responses. Using Positive Pressure Ventilation During a Fire and Rescue Response. Qualifications Hàndbook. 2017:1-36.

27. Koenig W. High-sensitivity C-reactive protein and atherosclerotic disease: From improved risk prediction to risk-guided therapy. Int I Cardiol 2013;168(6):5126-5134.

28. Hillyer M, Menon K, Singh R. The Effects of Dehydration on Skill-Based Performance. Int J Sport Sci. 2015;5(3):99-107

29. Masento N a, Golightly M, Field DT, Butter LT, van Reekum CM. Effects of hydration status on cognitive performance and mood. Br J Nutr. 2014;111(10):184152.

30. Ross M, Abbiss C, Laursen P, Martin D, Burke L. Precooling methods and their effects on athletic performance: A systematic review and practical applications. Sport Med. 2013;43(September):207-225.

31. Booth. J, Marino F, Ward JJ. Improved running performance in hot humid conditions following whole body precooling. Med Sci Sports Exerc. 1997;29(7):943-949.

32. Arngrïmsson SA, Petitt DS, Stueck MG, Jorgensen DK, Cureton KJ. Cooling vest worn during active warm-up improves 5-km run performance in the heat. $J$ Appl Physiol. 2004;96:1867-1874.

33. Siegel R, Maté J, Watson G, Nosaka K, Laursen PB. Pre-cooling with ice slurry 
ingestion leads to similar run times to exhaustion in the heat as cold water immersion. J Sports Sci. 2012;30:155-165.

520

521

522

523

524

525

526

527

528

529

530

531

532

533

534

535

536

537

538

34. Brearley M, Walker A. Water immersion for post incident cooling of firefighters; a review of practical fire ground cooling modalities. Extrem Physiol Med. 2015;4(1):15.

35. Walker A, Driller M, Brearley M, Argus C, Rattray B. Cold-water immersion and iced-slush ingestion are effective at cooling firefighters following a simulated search and rescue task in a hot environment. Appl Physiol Nutr Metab. 201+39(10):11591166.

36. Hull JD, Barton IP, Torgersen J, Mcneil CM. A Survey of the Experience and Impact of Acute Upper Respiratory Tract Infections on People in Six countries in the 2011 / 2012 Common Cold and Flu Season. 2013;3(Noveniber):175-187.

37. Mustajbegovic J, Zuskin E, Schachter EN, et al Respiratory function in active firefighters. Am J Ind Med. 2001;4e(1):55-62.

38. Ribeiro M, Santos ÃUDP, కussacos MA, Terra-filho M. Prevalence and risk of asthma symptoms among fireíighters in São Paulo, Brazil: a population-based study. Am J Ind Med. 2009;269·261-265.

39. Greven FE, Røoyackers ÃJM, Kerstjens HAM, Heederik DJ. Respiratory Symptoms in Firefighters. 2011;355:350-355.

40. Fent KW, Alexander B, Roberts J, et al. Contamination of firefighter personal protective equipment and skin and the effectiveness of decontamination procedures. $J$ Occup Environ Hyg. 2017;14(10):801-814.

41. Lusa S, Miranda H, Luukkonen R, Punakallio A. Sleep disturbances predict long-term changes in low back pain among Finnish firefighters: 13-year follow-up study. Int Arch Occup Environ Health. 2015;88(3):369-379. 
42. Fullerton CS, Ursano RJ, Wang L. Acute Stress Disorder, Posttraumatic Stress Disorder, and Depression in Disaster or Rescue Workers. Am J Psychiatry. 2004;161(8):1370-1376.

43. Berger W, Coutinho ESF, Figueira I, et al. Rescuers at risk: A systematic review and meta-regression analysis of the worldwide current prevalence and correlates of PTSD in rescue workers. Soc Psychiatry Psychiatr Epidemiol. 2012;47(6):1001-1911.

44. Walker A, McKune A, Ferguson S, Pyne DB, Rattray B. Chronic occupaticnal exposures can influence the rate of PTSD and depressive disorders in first yesponders and military personnel. Extrem Physiol Med. 2016;5(1):8.

45. Padgett DA, Glaser R. How stress influences the immune response. Trends Immunol. 2003;24(8):444-448.

46. Coris EE, Ramirez AM, Van Durme DJ. Heat Illness in Athletes: The Dangerous Combination of Heat, Humidity and Exercise. Sport Med. 2004;34(1):9-16.

47. Tokizawa K, Sawada S-I, Tai T, et al. Effects of partial sleep restriction and subsequent daytime napping on prolonged exertional heat strain. Occup Environ Med. $2015 ; 72(7): 521,529$

48. Abedelnialek 9 , Souissi N, Chtourou H, et al. Effects of partial sleep deprivation on proinfilanmatory cytokines, growth hormone, and steroid hormone concentrations during repeated brief sprint interval exercise. Chronobiol Int. 2013;30(4):502-9.

49. Wannamethee G, Shaper AG, Macfarlane PW, Walker M. Risk Factors for Sudden Cardiac Death in Middle-Aged British Men. Circulation. 1995;91(6).

50. Abbott A V. Diagnostic approach to palpitations. Am Fam Physician. 2005;71(4):743750.

51. Stewart S, Hart CL, Hole DJ, Mcmurray JJ V. A Population-Based Study of the Long- 
Table 1. Demographic details of both Fire Service Instructor and Firefighter survey

571 responders.

\begin{tabular}{lll}
\hline & Fire Service Instructor & Firefighter \\
\hline Age Mean \pm SD (yrs) & 43 & 7 \\
Age Standard Deviation (yrs) & 5 \\
Time as FSI Mean (yrs) & 5 \\
Time as FSI Standard Deviation (yrs) & 124 \\
Number of Male Participants & $95 \%$ \\
Percentage of Male Participants (\%) & $6 \%$ \\
Number of Female Participants &
\end{tabular}

Table 2. Ranking of wears in ercier of perceived physiological challenge, 1 being the easiest

575 to complete an 3 being the hardest. N/A for those that did not complete that wear type.

\begin{tabular}{lllll}
\hline Type of Wear & \multicolumn{5}{l}{$\begin{array}{l}\text { Perception of } \\
\text { Physiological Challenge }\end{array}$} \\
BA cold/no smoke & 78 & 2 & 3 & N/A \\
\hline CFBT & 9 & 66 & 24 & 1 \\
\hline & 16 & 32 & 60 & 2
\end{tabular}


Table 3. Fire Service Instructor and Firefighter perception of how they feel, both physically

578 and mentally, at the end of an average wearing week.

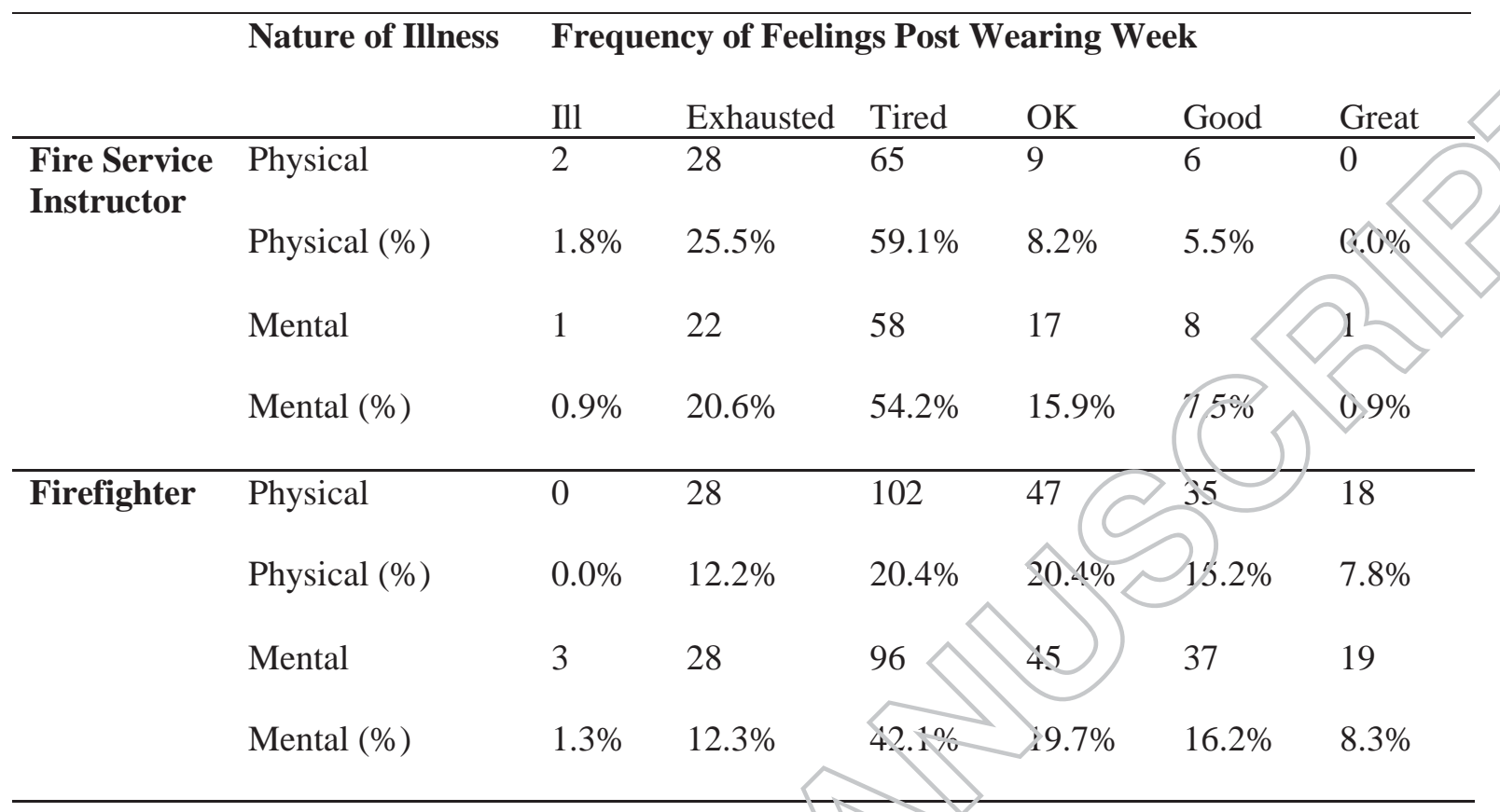

579 


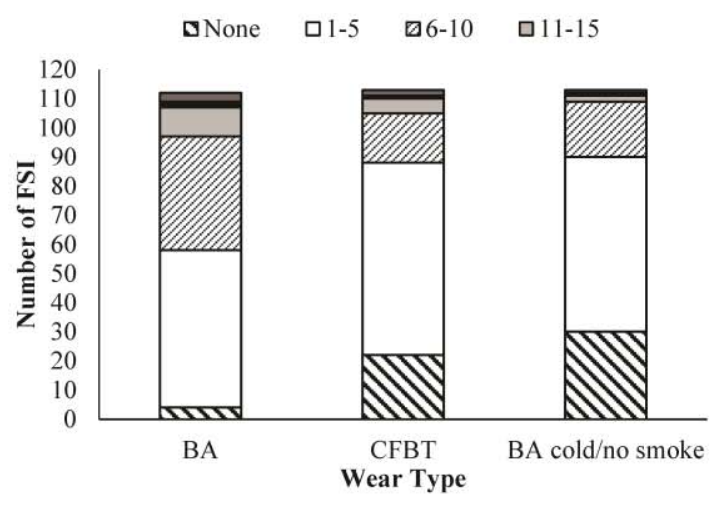

Figure 1

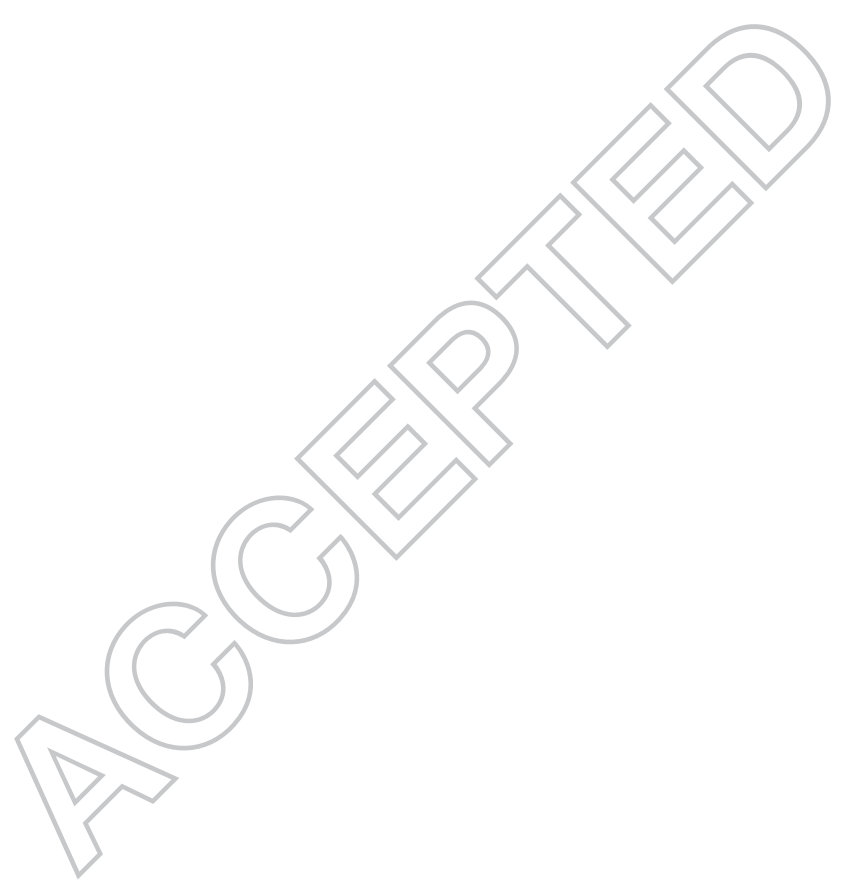

585 Figure 1. The number of FSI who completed each frequency of wear types during a one 586 month period. 


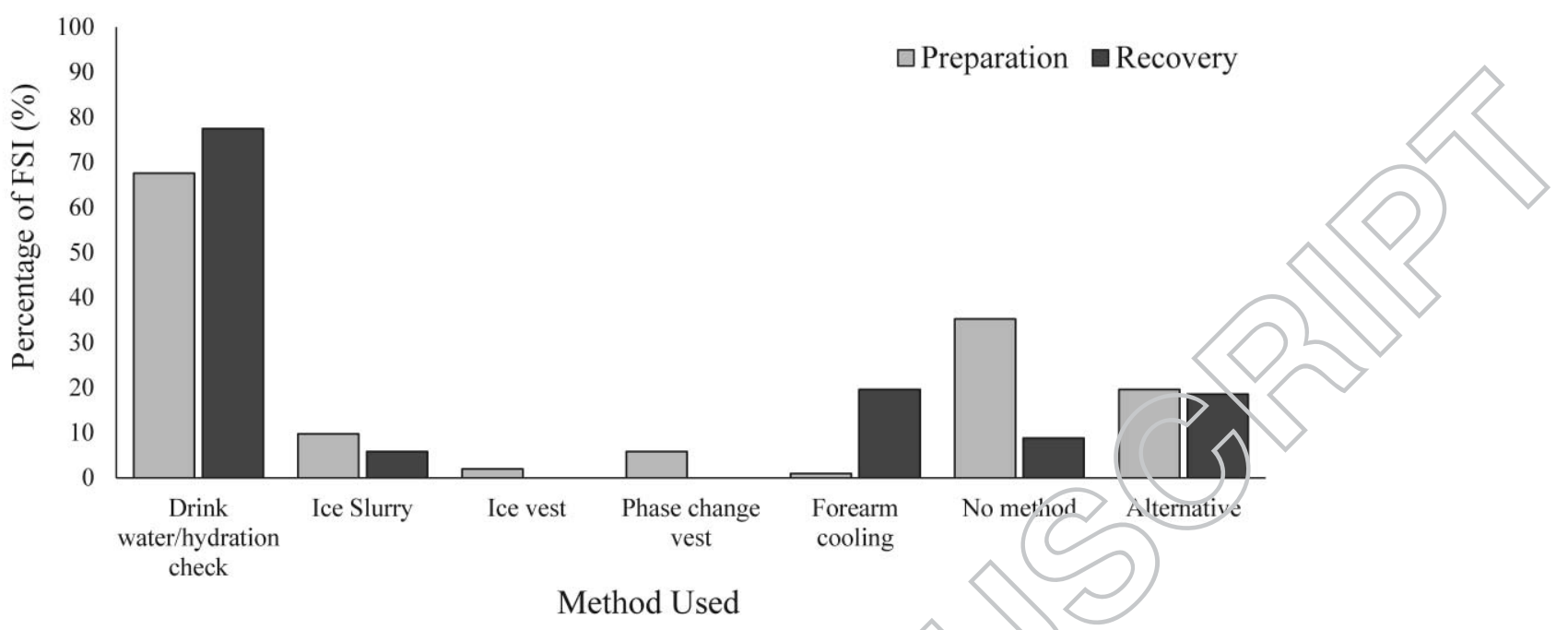

589

590 Figure 2. The percentage of FSI using different methods during the preparation and recovery

591 periods prior to and following a wear. The preparation graph represents 102 responders with

592144 method responses; the recovery graph represents 102 responders with 133 method

593 responses.

594 